\title{
A Wireless Instrumented Milling Cutter System with Embedded PVDF Sensors
}

\author{
Ming Luo ${ }^{a}$, Huan Luo $^{a}$, Dragos Axinte, ${ }^{b, c^{*}}$, Dongsheng $\operatorname{Liu}^{a}$, Jiawei Mei $^{a, b}$ and Zhirong Liao ${ }^{b}$ \\ $a$ Key Laboratory of Contemporary Design and Integrated Manufacturing Technology, Northwestern \\ Polytechnical University, Xi'an, P.R. China \\ $b$ Machining and Condition Monitoring Group, Faculty of Engineering, The University of Nottingham, \\ Nottingham, United Kingdom \\ c Faculty of Science and Engineering, The University of Nottingham Ningbo Campus, Ningbo, China
}

\begin{abstract}
Among all the monitoring data which could be captured in a machining process, the cutting forces could convey key knowledge on the conditions of the process. When the machining involves a single cutting edge the relationship between the output forces (measured with off-the-shelf dynamometers) and condition of the process, is somehow straight forward. However, when multiple cutting edges are in contact with the workpiece, the conventional dynamometers, that cannot separate the reaction forces on each cutting edge, loose significant information that could be used to in-detail monitor the machining process. To this end, this paper presents a novel concept of instrumented wireless milling cutter system with embedded thin film sensors in each cutting inserts, thus the cutting forces acting on each cutting edge could be monitored without reducing the stiffness and dynamic characteristics of the machining system. For this to happen, a dedicated milling force decoupling model for the developed instrumented milling cutter system is proposed and calibrated, and for the first time the accurate online estimation of the separate inserts' working conditions is achieved. The validation demonstrates a satisfactory agreement between the forces measured from the dynamometer and the proposed monitoring system prototype with the error less than $10 \%$. Furthermore, the experimental results also indicate that the monitoring system prototype could also identify the tool insert conditions such as worn and chipped, which could be of high relevance to the analysis of the insert failure mechanism and its progress. Not only the proposed method and easy implementable but above all, it allows the monitoring of the condition (e.g. worn, chipped) of each insert, ability that has not been previously reported.
\end{abstract}

Keywords: Cutting forces; Tool wear; Sensor; Smart tool 


\section{Introduction}

With the demand of increasing the performance and the life of critical parts in industry (e.g. aerospace, moulds \& dies industries), there is a growing trend of applying intelligent manufacturing processes. In this respect, one of key enablers for intelligent machining operations is process monitoring that needs to provide timely, reliable and detailed information during the whole process. Among all the monitored variables in machining process, cutting force is one of the most important signals since it is highly related with cutting conditions such as tool wear [1,2], machining vibration [3] and surface integrity [2] etc. Currently, off-the-shelf cutting force monitoring devices, e.g. piezoelectric-based dynamometers, are mainly adopted to conduct data collection or machining process optimization to allow control of the machining process. However, this intrusive approach faces significant challenges: (1) Such devices are usually mounted on the tooling/machine tools with detrimental effect on the system stiffness and dynamic characteristics, thus the data collected may not be very representative for the real system without these devices; (2) As such systems are, in general, difficult to fit within industrial setups, most published data is generally collected/analysed under specific conditions, e.g. research labs; thus, these lead to the need to perform repeated "calibrations" to enable the use of these techniques in real environments, which is not trivial neither time/cost efficient.

To improve the monitoring ability of the machining process, embedding small sensors like acoustic emission and force sensors in the machine tool or fixtures has been proposed [4]. One of the simple and convenient methods for machining process monitoring is to use current signals or sever motors to monitor the machining process, then the recorded signals are used to derive the cutting forces in the machining process $[5,6]$. However, this kind of signals are far from accurate to be used for machining process diagnosis. For example, chipped insert can be detected based on the relationship between spindle power and cutting forces [7], but the exact insert which is chipped cannot be identified. To get more accurate data from the machining process, integrating sensors or monitoring devices with machine tools and fixtures is a feasible method in workshop, which could record machining data during the machining process. Shi and Gindy [8] developed a monitoring system to detect tool malfunctions for machining processes by integrating strain sensor, accelerometer and power sensor into the machine tool. Li et at. [9] developed a responsive fixture by embedding piezoelectric pressure sensor and eddy current displacement sensor into the fixture to ensure the precision machining of large-scale aerospace parts. Totis et al. [10] integrated tri-axial force sensor into the cutter to form a rotating dynamometer for cutting force measurement in face milling. However, the high cost of this kind of sensors makes it unaffordable in the workshop. 
To achieve more compact monitoring method, small but low cost force sensors are being developed. Such sensors, including Fibre Bragg grating sensor [11], surface acoustic wave strain sensor [12], semi-conductive strain gauge [13], and piezoelectric sensors [14], can be utilised for milling process monitoring. With the high sensing performance, these kind of sensors could be made in very small size, especially the thickness of the sensor could be reduced to one-layer thin film [15]. These sensors are easy to use, and can be integrated with existing equipment and fixture compactly. Because of the above advantages, some remarkable applications have been achieved by integrating and embedding thin film sensor elements into the structure body to sense the cutting forces [16] and pressure [17], while the signals are sent out by wired connection or wireless transmission methods. Also, some sensor solutions have been applied to milling process monitoring, for which Polyvinylidene fluoride (PVDF) films were glued to the cutter shank with validated effectiveness and advantages $[14,16]$. However, in these reports the measured outputs are the resultant forces acting on all cutting teeth simultaneously, and for this reason such measured forces have significant limits if the interaction between a single cutting edge and the workpiece needs to be investigated. Marinescu and Axinte [18] used acoustic emission (AE) sensory measures for monitoring tool edge and/or workpiece surface anomalies in milling operations, cutting edge malfunctions monitoring in multi-teeth cutting can be done by AE but it is very expensive as computing power.

Thus, on reviewing of current solutions for cutting force measurement, it appears to be limited/scarce reports on how monitoring setups could be constructed so that the interaction between a single cutting edge and the workpiece could be captured in operations, e.g. milling, when multiple edges engage the machined part. This not only limits the deeper understanding of the phenomena occurring at the level of single cutting edge in milling operations but also reduces the possibility to take actions during the process if malfunctions occur (e.g. chipped, wear). Therefore, measuring the single phase forces acting on each flute or insert is required and could be the further step of the thin film sensors' application.

In this paper, to address the research gap of measuring single phase forces of each insert, a novel instrumented milling cutter system with embedded thin film sensors is proposed, modelled and validated. To monitor the 3-axial specific cutting forces acting on single milling tooth, thin film sensors are embedded into the seat of each cutting insert. Based on the monitored data from this sensory system, for the first time the accurate on-line estimation of the separate inserts' working conditions is achieved. Because of the specific design of the cutting inserts, the thin film sensors are not orthogonally arranged and this results in directional cross-talk of the output signals from each sensor. To address 
this challenge, a dedicated 3-axis force decoupling model for the developed instrumented milling cutter system has been developed. To validate the developed monitoring solution and models, milling tests have been conducted with the instrumented cutter on which single cutting edges at different status (e.g. new, worn and chipped) have been employed in machining conditions when multiple cutting edges are in contact with the workpiece. The proposed monitoring system/solution proved its efficiency in capturing/identifying the malfunctioned cutting edge.

\section{Instrumented milling cutter sensing system}

The proposed sensing system (Fig.1) consists of a set of PVDF thin film sensors which are placed under the insert seats of a milling cutter (see detail Fig. 1), a charge amplifier, a wireless transmitter unit with high speed A/D converter and a data receiver. The employed PVDF thin film sensors, with the working frequency up to $10 \mathrm{MHz}$ and thickness from $10 \mu \mathrm{m}$ to hundreds of microns, have the linear electromechanical interaction between the mechanical and the electrical state in crystalline materials [19], leading to the wide range of the applications in industry such as energy harvesting [20], vibration monitoring and control [21], dynamic force measurement and intelligent working condition monitoring [22].

To measure the cutting forces acting on separate insert in milling process, the sensors should be placed as close as possible to the cutter to generate the accurate electric charges when the cutting forces are applied on the insert and its seat. Therefore, the PVDF sensors are placed between the seat and its mounting surface of the cutter shank (see Fig.1). Electric charges will be generated on the sensors once cutting forces is applied on the insert and seat. Then the charge amplifier outputs a voltage according to the generated electric charges. After the analogue-to-digital convert, the force signals are transmitted by the wireless transmitter. At the receiving end, the receiver receives the signals and sends to the computer for further signal processing. 


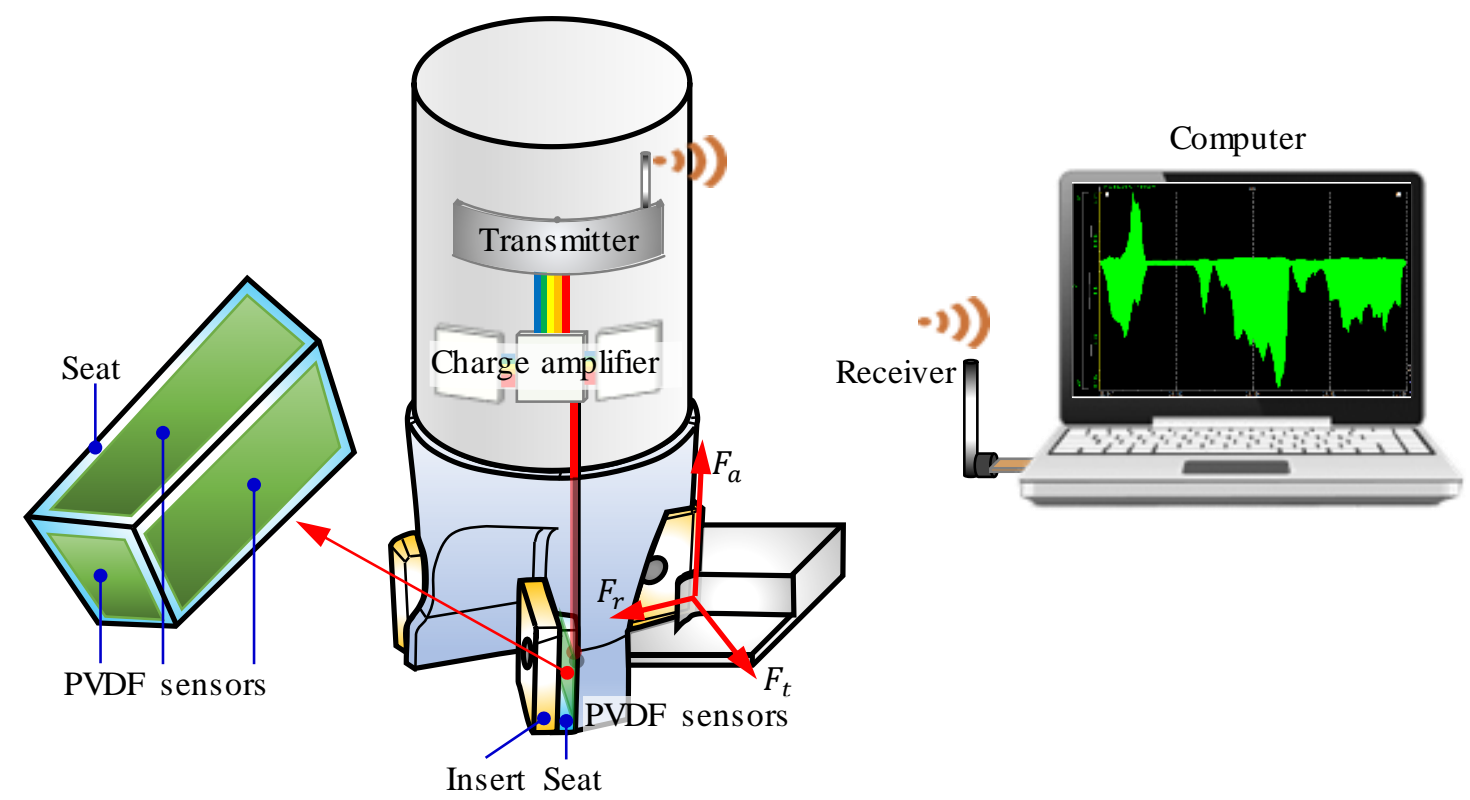

Fig. 1. Schematic diagram of the wireless instrumented milling cutter system with embedded PVDF sensors.

\subsection{Milling force decoupling}

A simple cutter body-insert module is presented in Fig. 2(a) to show its structure. Generally, the cutting forces acting on the insert could be decomposed into three directions: tangential $\left(F_{t}\right)$, radial $\left(F_{r}\right)$ and axial $\left(F_{a}\right)$ cutting forces. To sense these forces, as shown in Fig. 2(b) and (c), three PVDF sensors are placed on the bottom and side faces of the insert to record the dynamic cutting forces. However, as shown in Fig. 2(d), the measured forces: $F_{1}, F_{2}$ and $F_{3}$ corresponding to PVDF 1, 2 and 3 shown in Fig. 2(b) and (c), are not all parallel with the $F_{t}, F_{r}$ and $F_{a}$, thus a cross-talk will be introduced since there will be forces on other directions when a force is applied along one direction. Therefore, a decoupling model of the forces measured from the PVDF sensors is required to export the $F_{t}, F_{r}$ and $F_{a}$ acting on the insert. 


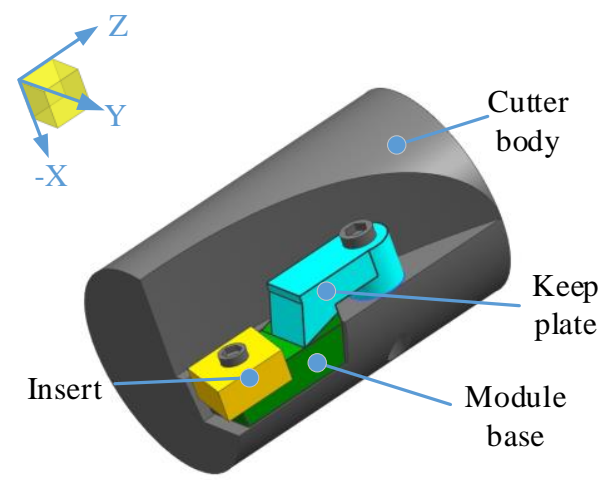

(a)

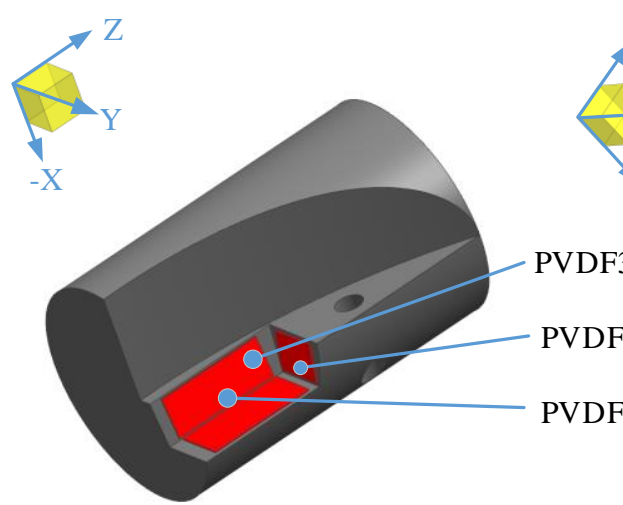

(b)

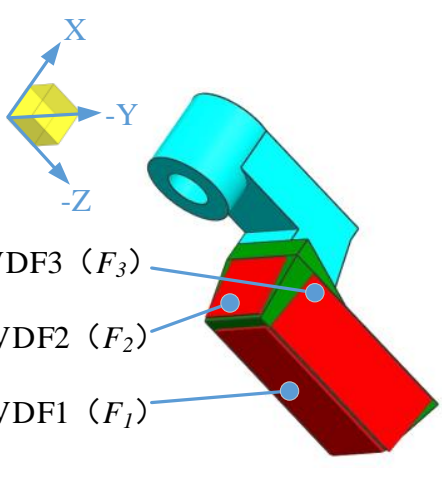

(c)

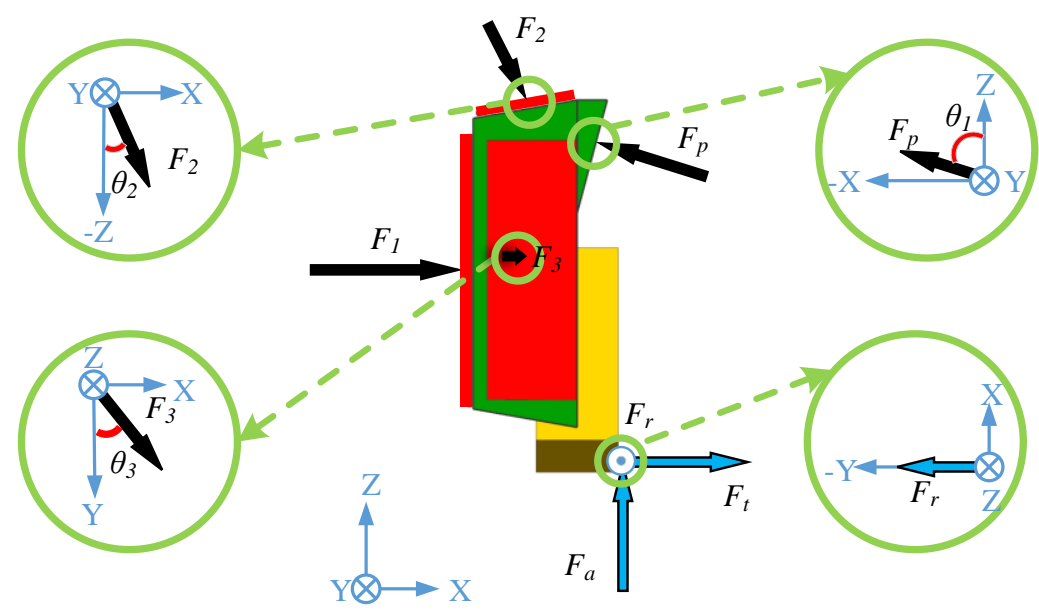

(d)

Fig. 2. Spatial relationship between the PVDF sensors and the cutting body, including: (a) the general view of the whole cutting body, the relative positions of the PVDF sensors and (b) the cutter body and (c) the module base, (d) the force analysis of the integrated PVDF sensors.

Based on the forces analysis presented in Fig. 2(d), according to the balance of the forces on the insert, the following formulas can be derived:

$$
\begin{aligned}
& F_{1}+F_{t}+F_{2} \sin \theta_{2}+F_{3} \sin \theta_{3}-F_{p} \sin \theta_{1}=0 \\
& F_{3} \cos \theta_{3}-F_{r}=0 \\
& F_{a}-F_{2} \cos \theta_{2}+F_{p} \cos \theta_{1}=0
\end{aligned}
$$

$F_{p}$ is the force acting on the inclined face as shown in Fig. 2(d), $\theta_{1}$ is the angle between $F_{p}$ and $Z$ axis, $\theta_{2}$ is the angle between $F_{2}$ and $Z$ axis, and $\theta_{3}$ is the angle between $F_{3}$ and $Y$ axis. In order to decouple forces acting on the PVDF sensors, a rotational equilibrium equation about $X$ axis direction is derived as:

$$
F_{3} l_{3} \cos \theta_{3}-F_{r} l_{r}+F_{a} l_{a}-F_{2} l_{2} \cos \theta_{2}+F_{p} l_{p} \cos \theta_{1}=0
$$


where $l$ is the corresponding arm of forces. By solving equations (1)-(4) simultaneously, the relationship can be derived as:

$$
\left[\begin{array}{l}
F_{t} \\
F_{r} \\
F_{a}
\end{array}\right]=\left[\begin{array}{ccc}
-1 & A & B \\
0 & 0 & C \\
0 & D & E
\end{array}\right]\left[\begin{array}{l}
F_{1} \\
F_{2} \\
F_{3}
\end{array}\right]
$$

where A, B, C, D and E are decoupling coefficients and can be expressed as follows.

$$
\begin{aligned}
& \mathrm{A}=-\sin \theta_{2}-\frac{\tan \theta_{1} \cdot \cos \theta_{2} \cdot\left(l_{a}-l_{2}\right)}{l_{\mathrm{p}}-l_{a}} \\
& \mathrm{~B}=-\sin \theta_{3}-\frac{\tan \theta_{1} \cdot \cos \theta_{3} \cdot\left(l_{3}-l_{r}\right)}{l_{\mathrm{p}}-l_{a}} \\
& \mathrm{C}=\cos \theta_{3} \\
& \mathrm{D}=\frac{\cos \theta_{2} \cdot\left(l_{\mathrm{p}}-l_{2}\right)}{l_{\mathrm{p}}-l_{a}} \\
& \mathrm{E}=\frac{\cos \theta_{3} \cdot\left(l_{3}-l_{r}\right)}{l_{\mathrm{p}}-l_{a}}
\end{aligned}
$$

In the milling test with single insert, cutting forces can be measured with both instrumented cutter $\left(F_{1}\right.$, $\left.F_{2}, F_{3}\right)$ and table dynamometers $\left(F_{t}, F_{r}, F_{a}\right)$ at the same time. By submitting these data into equation (5), the above five parameters can be calibrated. Usually at least five groups of data should be used for calibration to get accurate calibration results.

\subsection{Charge calculation for PVDF sensors}

The PVDF sensor has a multilayer sandwich structure consisting of a PVDF film, electrodes and protective coatings (see Fig. 3a), both sides of PVDF film are covered by electrodes, and the whole structure is wrapped by coatings for protection and insulation. To compute the electric charges generated by the mechanical strains of the sensor due to applied force component, the electric displacements $D$ needs to be integrated over the electrode areas as follows [23]:

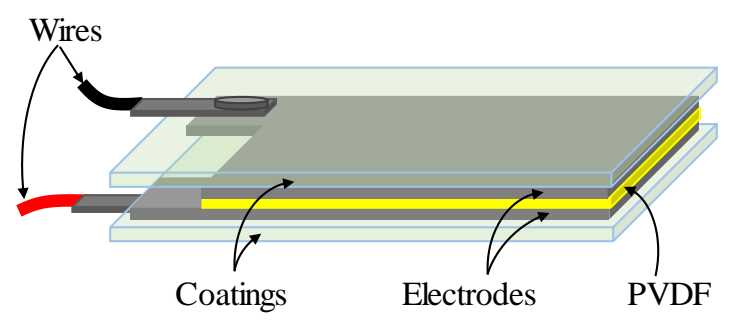

(a)

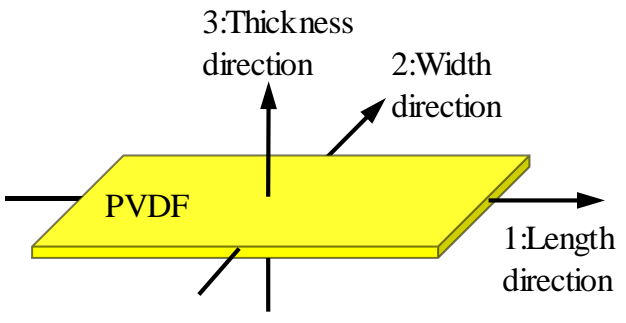

(b)

Fig. 3. The general model of the PVDF sensor, including: (a) the structure and (b) the sensitivity directions of the PVDF sensor.

$$
q=\iint\left[\begin{array}{lll}
D_{1} & D_{2} & D_{3}
\end{array}\right]\left[\begin{array}{l}
d A_{1} \\
d A_{2} \\
d A_{3}
\end{array}\right]
$$


where $A_{1}, A_{2}$ and $A_{3}$ are the components of the electrode area in the 2-3,1-3 and 1-2 planes of the sensor (see Fig. 3b), respectively [19]. Please note the $i$-j denotes the plane formed by $i$ and $j$ axes in Fig. 3(b).

Since the PVDF element can be treated as orthotropic material after being poled with the symmetry axes coincident with the geometric axes while the thickness of the PVDF sensor is very small, the sensor can be assumed to be in plane stress state [19]. Therefore, assuming the load is applied only on the normal face of the sensor, the expression for charge induced can be reduced from (4) as:

$$
q=\iint D_{3} d A_{3}
$$

For a PVDF thin film sensor, if the pressure is applied on the normal face, the strain mainly exists in the normal direction, and the shear strain caused by torsion or slide could be neglected since the PVDF sensor is insensitive to the in-plane shear strain. Thus the charged induced in element area $d A_{i}$ can be derived as:

$$
q_{i}=d_{33} \sigma_{i} d A_{i}=d_{33} d F_{i}
$$

where $d_{33}$ is the piezoelectric constant in the 3 direction and the stress $\sigma_{i}$ can be expressed as [24]:

$$
\sigma_{i}=d F_{i} / d A_{i}
$$

\subsection{Signal processing}

In order to record the signals induced by the cutting forces, the output charge is converted to voltage by a charge amplifier and then filtered by a filter circuit. The output voltage of charger amplifier can be expressed as [19]:

$$
V=q / C_{f}
$$

where $C_{f}$ is the electric capacitance of the circuit feedback loop, and it could be calibrated by the experiments.

Considering the pressure over the sensor is evenly distributed, the output voltage is then related to the applied force $F$ by the relation:

$$
V=\frac{d_{33}}{C_{f}} F
$$

Since an insert usually has three faces where sensors are attached, a choosing circuit is used to select signals from the three circuits connected to the sensors in sequence, and then the chosen signal can be transmitted. The sampling frequency of the choosing circuit is set to high enough $(10000 \mathrm{~Hz})$ to avoid 
signal distortion.

Using $V_{1}, V_{2}$ and $V_{3}$ to denote the output voltages from the sensors, by combining (5) and (16), the relationship between the applied cutting forces in three directions and output voltages can be established as:

$$
\left[\begin{array}{l}
F_{t} \\
F_{r} \\
F_{a}
\end{array}\right]=\frac{C_{f}}{d_{33}}\left[\begin{array}{ccc}
-1 & A & B \\
0 & 0 & C \\
0 & D & E
\end{array}\right]\left[\begin{array}{l}
V_{1} \\
V_{2} \\
V_{3}
\end{array}\right]
$$

\section{Validation and discussion of milling force monitoring for separate insert}

In this section, an instrumented milling cutter prototype with embedded PVDF sensors is presented and the validation results in milling process with new, worn and chipped cutters are described.

\subsection{Instrumented milling cutter prototyping with three sensors}

To validate the proposed sensing cutter system, an instrumented cutter modified from the commercial available indexable milling cutter was developed, the cutting insert used here is MITSUBISHI APMT1135PDER-M2 VP15TF, the diameter of the cutter is $32 \mathrm{~mm}$. For simplicity, three PVDF sensors were placed on planar face under the modular base. As shown in Fig. 4, the insert was fixed to the modular base by means of preloading screw. The modular base was then clamped by the keep plate, which was fixed to cutter body by screw. The advantages for using modular base lies in the applicability for different types of insert. A spacer was placed between the keep plate and the cutter body, which has an inclined plane with the same angle on the modular base. One PVDF sensor was placed between the bottom surface of the modular base and the cutter body. When the keep plate is preloaded by the screw, preload is also applied on the PVDF sensors.

The keep plate was fixed with bolt and connected to the cutter body. In this case, preload was applied on all the PVDF sensors through the modular base. Since the thickness of the PVDF sensor is very small and with inclined planes design, the modular base would not slide or rotate when the cutting force is applied on the insert, and it could be assumed that only normal pressure forces are applied on the PVDF sensors. Thus the shear effect of the sensor is neglected. 


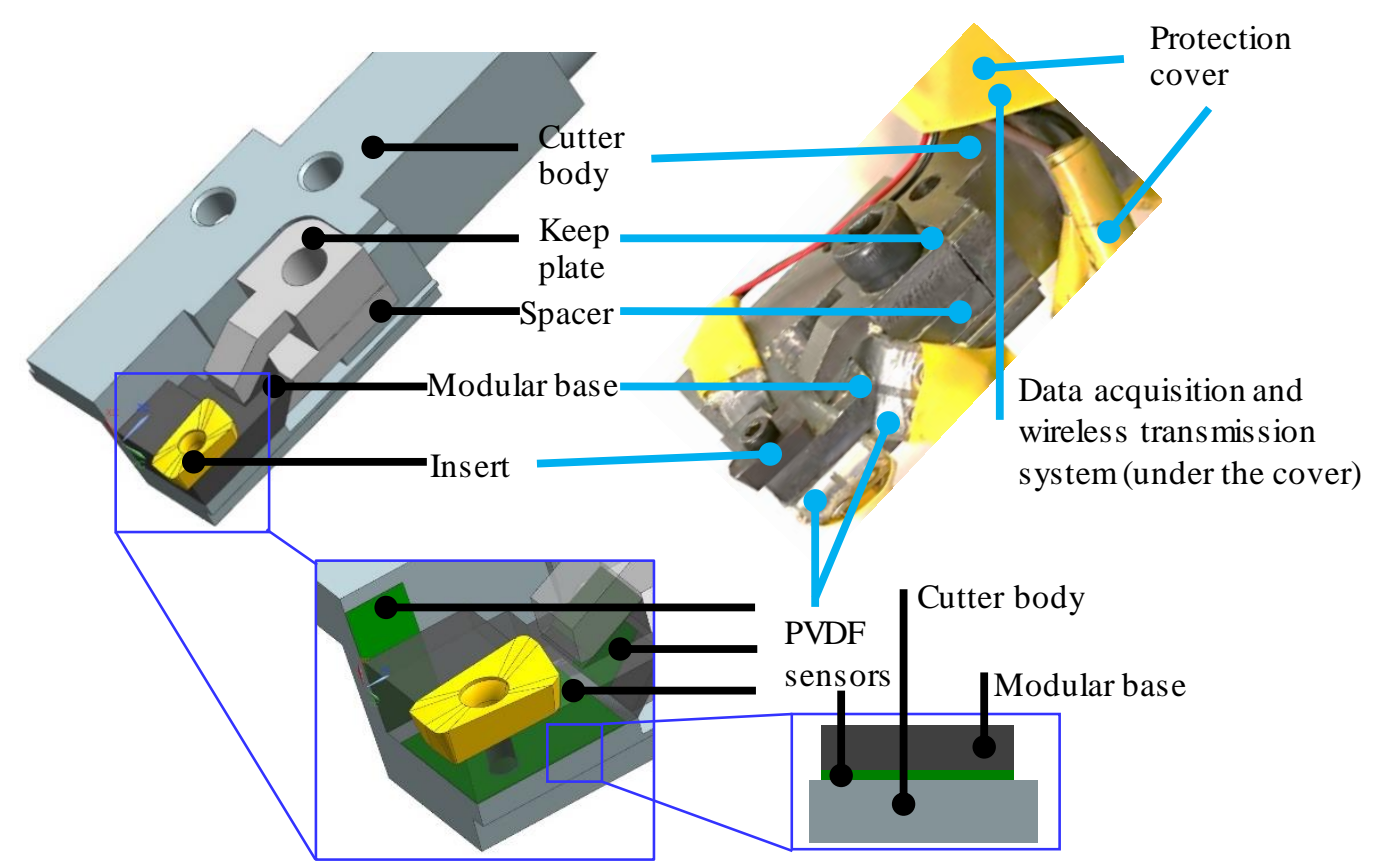

Fig. 4. The structure of the developed instrumented milling cutter with embedded PVDF sensors.

\subsection{Natural frequency analysis}

The natural frequency of the instrumented tool was investigated by the modal testing, and the results for the cutter as well as for the three sensors at one insert position are shown in Fig. 5. For the cutter, the impact point is the tool tip, the impact is along radial, axial and tangential directions of the cutting insert. The first order natural frequency of the instrumented tool directly determines the frequency response of the measuring arrangement. The modal testing results demonstrate that the dominant modes of the cutter and PVDF sensors are larger than $1100 \mathrm{~Hz}$, indicating that such measuring system is suitable for most of the milling processes, in which the tool passing frequencies are usually below $1000 \mathrm{~Hz}$. 

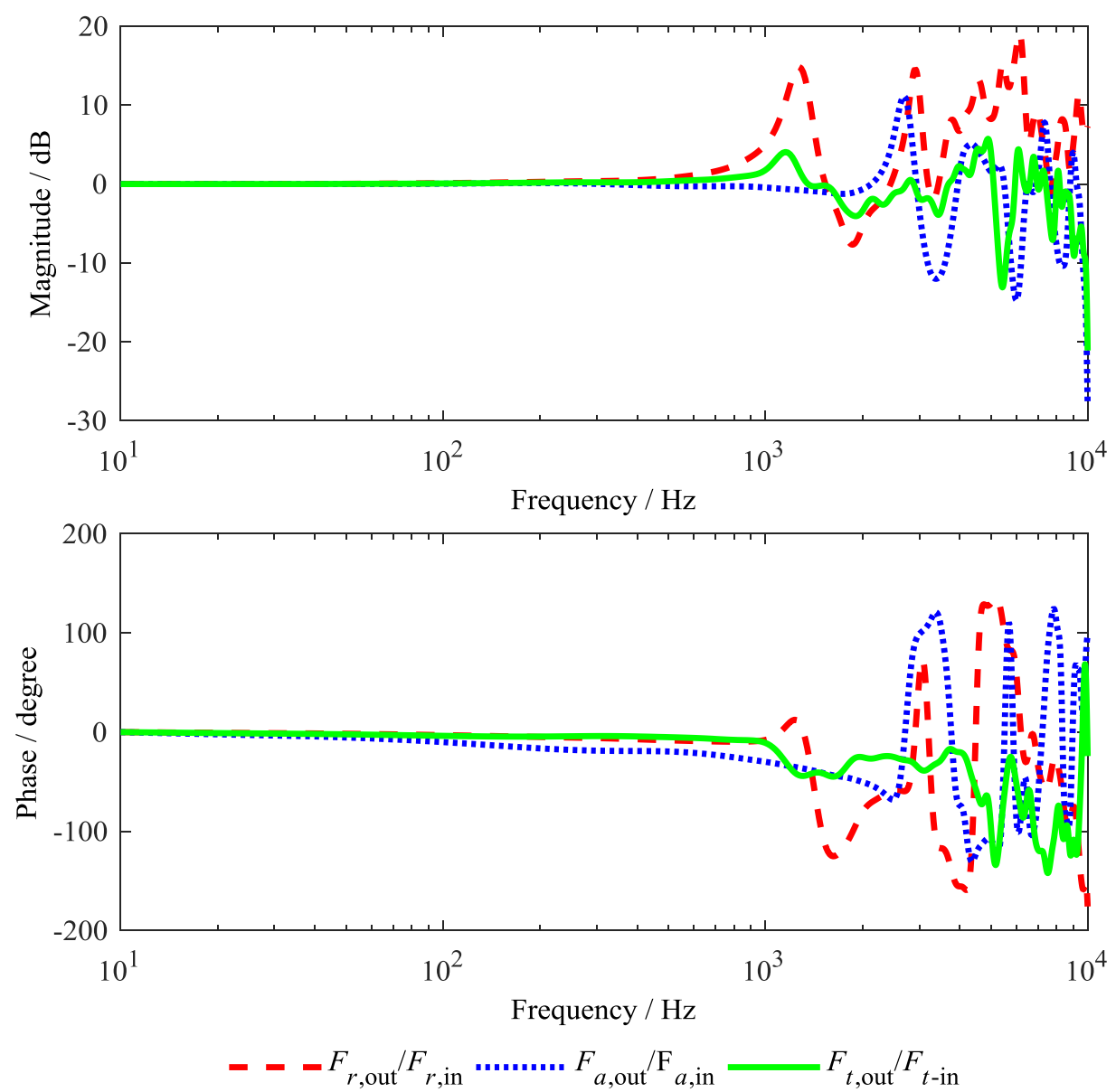

Fig. 5. Modal testing results for the instrumented cutter.

\subsection{Wireless transmission}

In milling process, when the dynamic cutting forces are applied on the PVDF thin film sensors, electric charges will be generated on the surface of the thin film. The electric charge is then amplified by the charge amplifier and converted to voltage signals. The voltage signals are then amplified by the preamplifier unit and sent to the interference signal filtering and suppression unit. After that, voltage signals collected by the 16bit high speed analog to digital converter (16bit high speed ADC). Processed signals are then sent to a high-speed DSP processor, which will then send the digital signals to the transmitter. The system block diagram for the on-shell data acquisition and wireless transmission system is shown in Fig. 6. The power of the entire circuit is about $2.1 \mathrm{~W}$, and a $5 \mathrm{~V}$ battery is used as the power supply. 


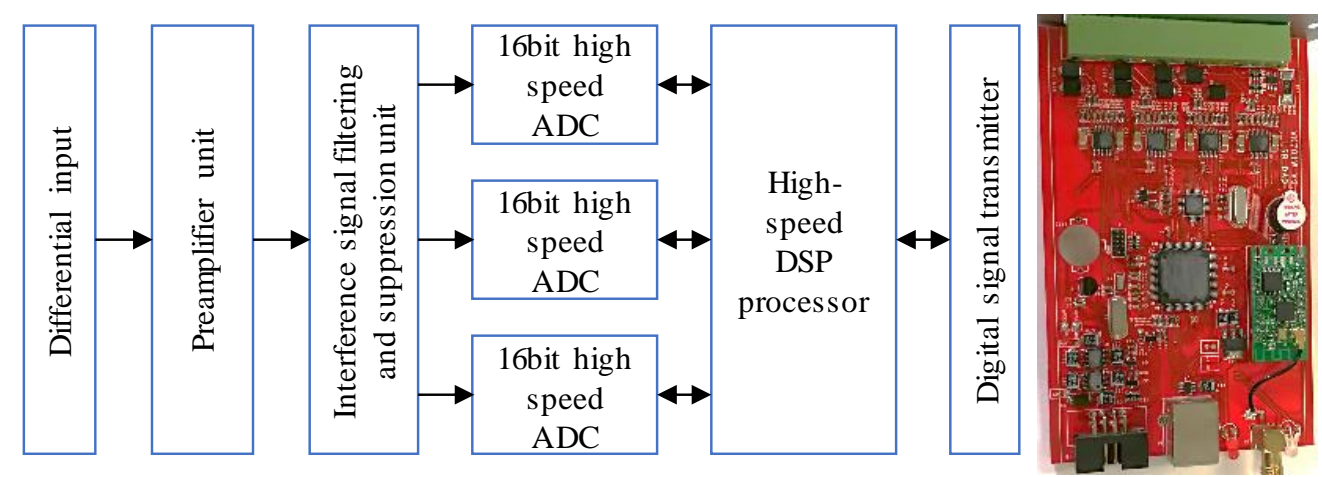

Fig. 6. System block diagram and circuit board for the on-shell data acquisition and wireless transmission system.

\subsection{Calibration and validation of the instrumented milling system}

To study the sensing performance of the instrumented milling cutter system, calibration has been conducted first. The workpiece material was Aluminium alloy 7075 , the spindle speed was $600 \mathrm{r} / \mathrm{min}$, and the feedrate was $100 \mathrm{~mm} / \mathrm{min}$. The axial cutting depth was $0.9 \mathrm{~mm}$ and radial cutting depth was $0.3 \mathrm{~mm}$, up milling method was applied in the calibration process. A new insert was used in the test, a table dynamometer Kistler 9257B was used to record cutting force acting on the workpiece. The sampling frequency for each channel of the dynamometer and the instrumented cutter was set to $10 \mathrm{kHz}$. During the cutting test, both signals from the dynamometer and the instrumented cutter were recorded. According to calibration method presented in Section 2.1, $N$ groups of data were selected for solving unknown parameters in (5). Taken $A$ and $B$ as example, by using $F_{t}$ and $F_{1}, F_{2}, F_{3}$, the following equations can be obtained based on (5):

$$
\left[\begin{array}{ccc}
F_{1}^{1} & F_{2}^{1} & F_{3}^{1} \\
F_{1}^{2} & F_{2}^{2} & F_{3}^{2} \\
\cdots & \cdots & \cdots \\
F_{1}^{N} & F_{2}^{N} & F_{3}^{N}
\end{array}\right]\left[\begin{array}{c}
-1 \\
A \\
B
\end{array}\right]=\left[\begin{array}{c}
F_{t}^{1} \\
F_{t}^{2} \\
\cdots \\
F_{t}^{N}
\end{array}\right]
$$

There are two undetermined parameters in the above equation, but there are $N>2$ groups of data. Therefore, the above equation forms morbid contradictory equations and it can be simplified as:

$$
M N=F_{t}
$$

Where $M$ is a column full rank matrix, let $M^{T}$ be the transpose matrix of $M$, then $M^{T} M$ is real symmetric positive definite matrix. By multiplying $M^{T}$, equation (19) can be changed to the following

$$
M^{T} M N=M^{T} F_{t}
$$

By using least squares method, the solution for equation (20) can be get. The same procedure can be used for solving $C, D$, and $E$. Finally, the five calibrated parameters are:

$$
\left\{\begin{array}{c}
A=0.0319 \\
B=0.1618 \\
C=0.6426 \\
D=-1.4212 \\
E=-0.0081
\end{array}\right.
$$


To validate the calibration results, a worn insert was assembled on the cutter to conduct the trials, and the cutting parameters were the same as above. Cutting forces from both the dynamometer and the instrumented cutter are compared and shown in Fig. 7, confidence interval for average cutting forces are shown in Fig. 8. Results show that both the profile and amplitude coincide with each other well, which demonstrates the effectiveness of the instrumented cutter system. Therefore, the developed instrumented cutter can be used for monitoring cutting forces acting on each insert, thus can be further used for tool condition monitoring.

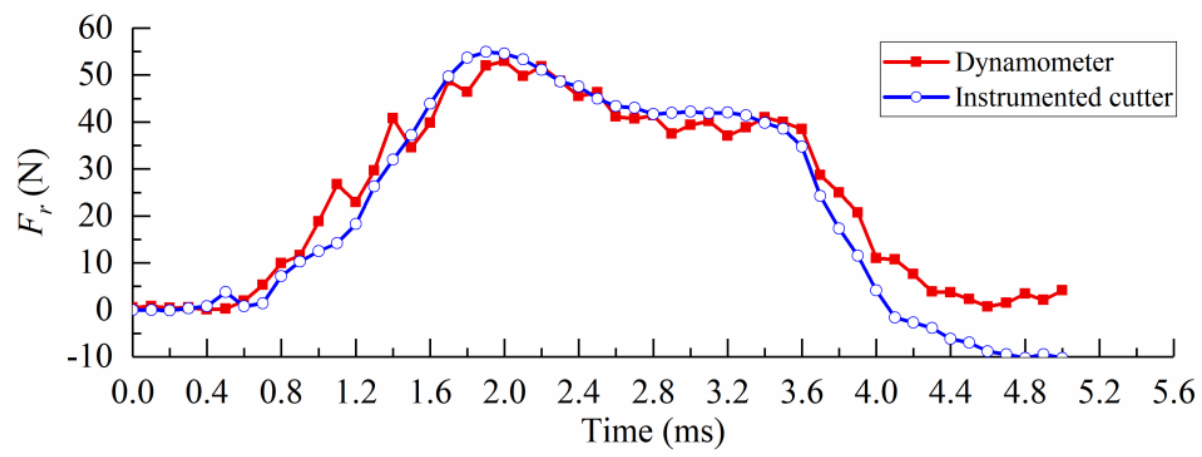

(a)

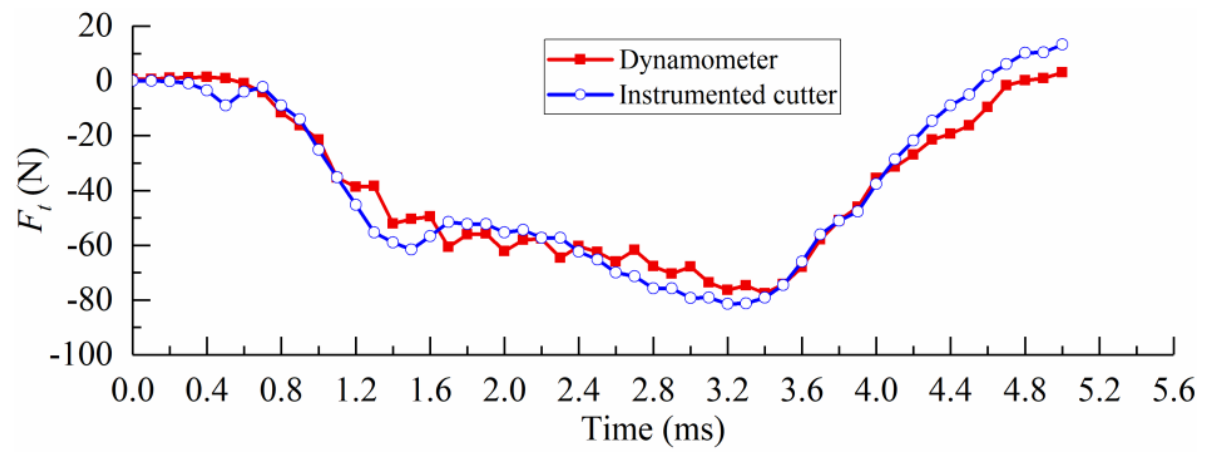

(b)

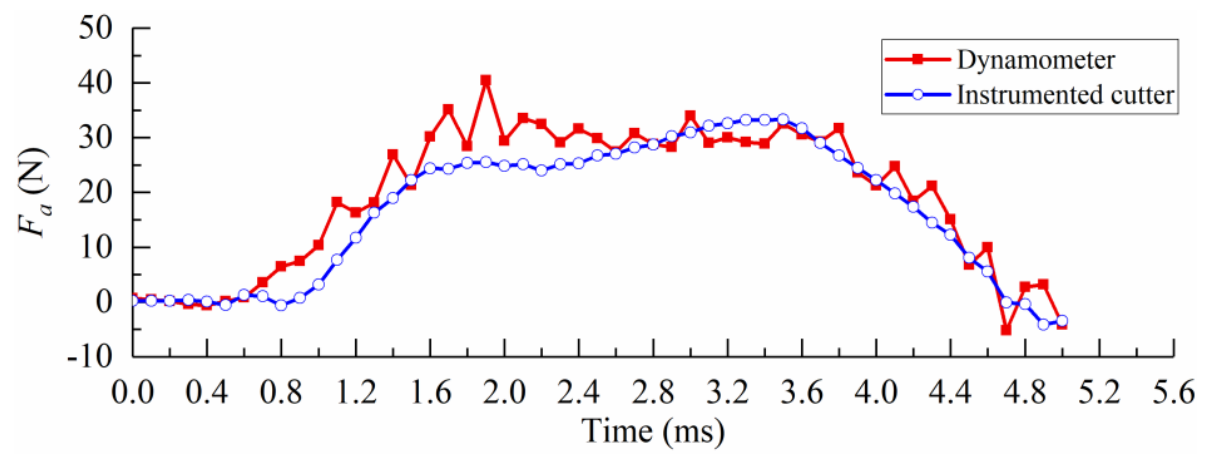

(c)

Fig. 7. Comparison of cutting forces measured from the dynamometer and the instrumented cutter. (a) Radial direction. (b) Tangential direction. (c) Axial direction. 


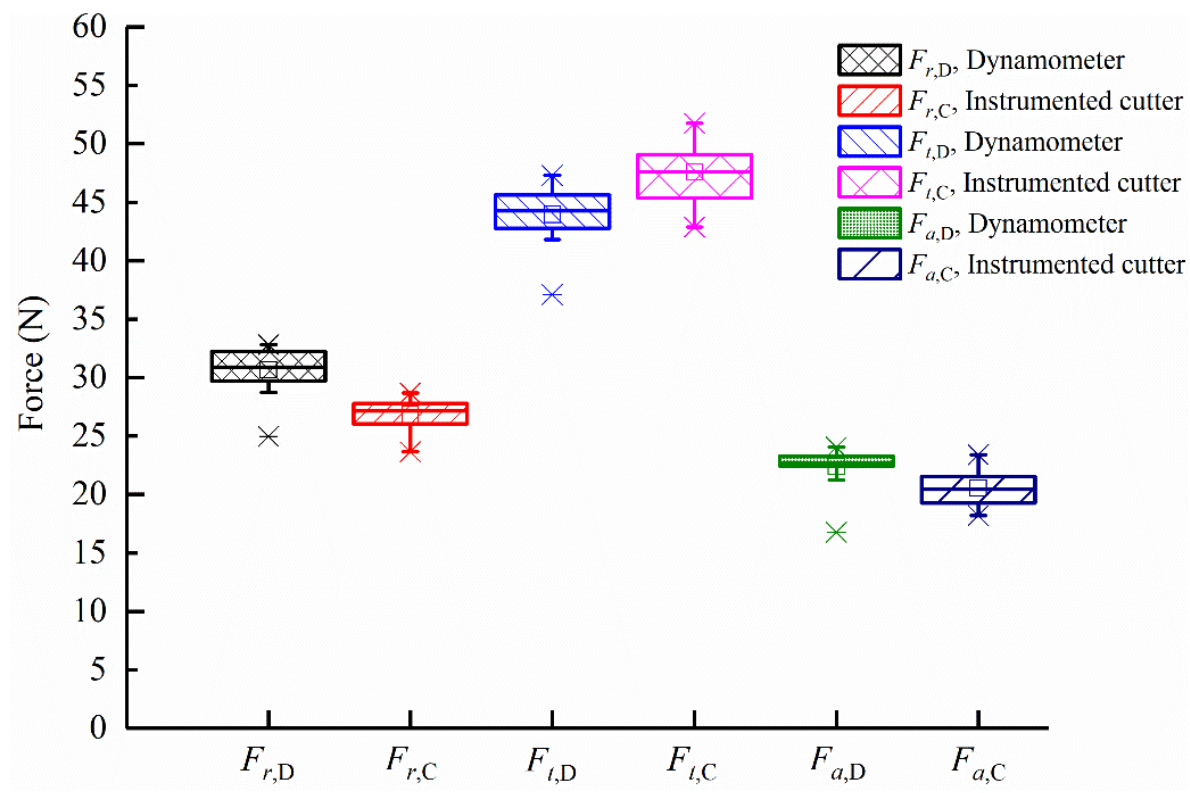

Fig. 8. Confidence interval for average cutting forces from the dynamometer and the instrumented cutter.

To further validate the developed instrumented cutter, a 2 levels Design of Experiments (DoE) with new insert were carried out: two spindle speed $1000 \mathrm{rpm}$ and $1500 \mathrm{rpm}$, two axial cutting depth $0.4 \mathrm{~mm}$ and $0.6 \mathrm{~mm}$. Sampling frequency of each channel for both the dynamometer and the instrumented cutter is set to 20kHz. Experimental results are shown in Fig. 9 in terms of forces in the radial, tangential and axial directions, the radial cutting depth was set to $0.5 \mathrm{~mm}$. Results show that both the profile and amplitude coincide with each other well except some small deviation, which demonstrates the effectiveness of the instrumented cutter system.
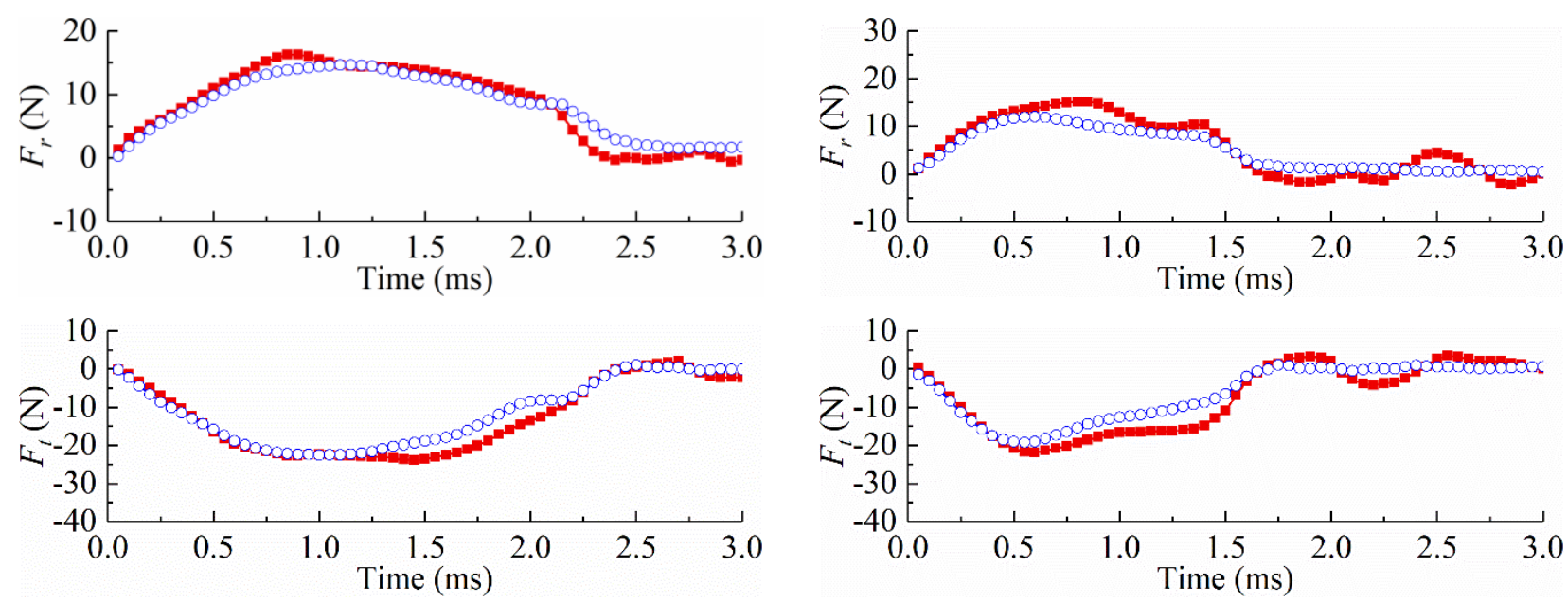


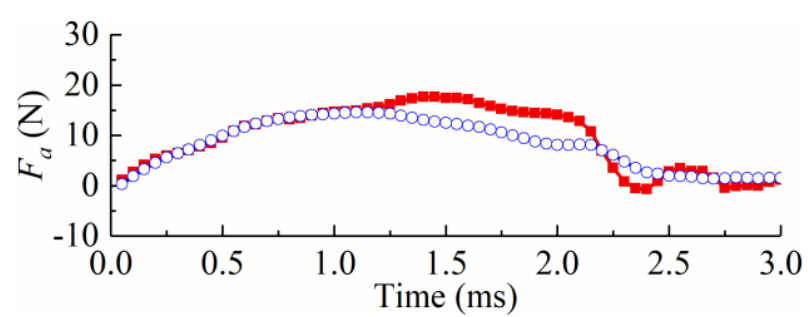

(a)
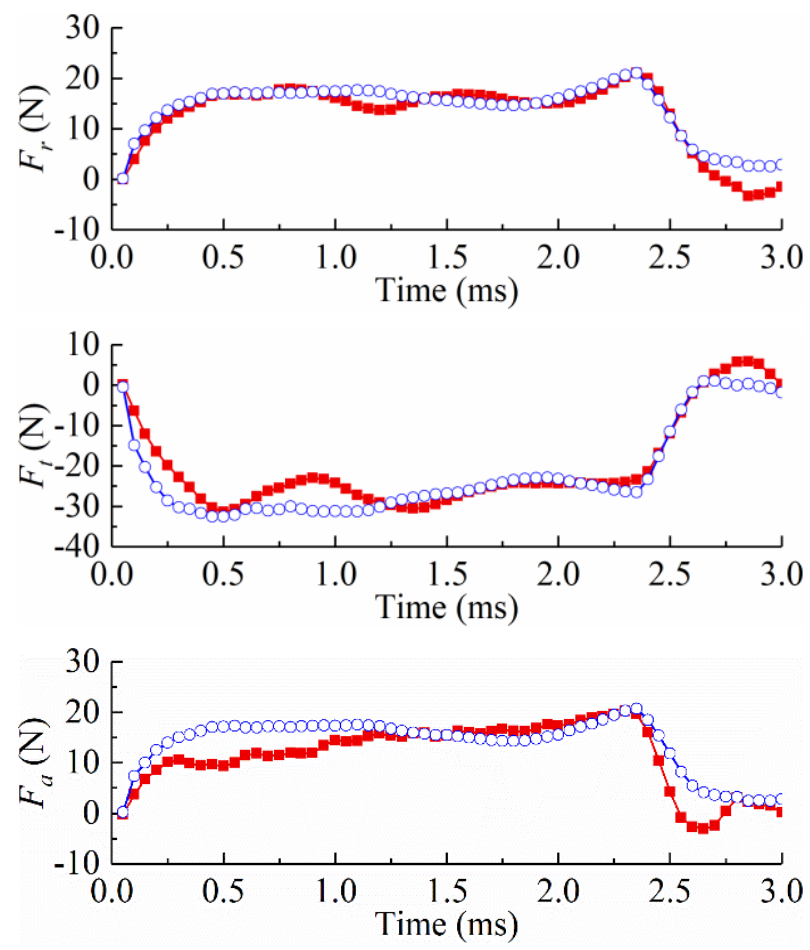

(c)

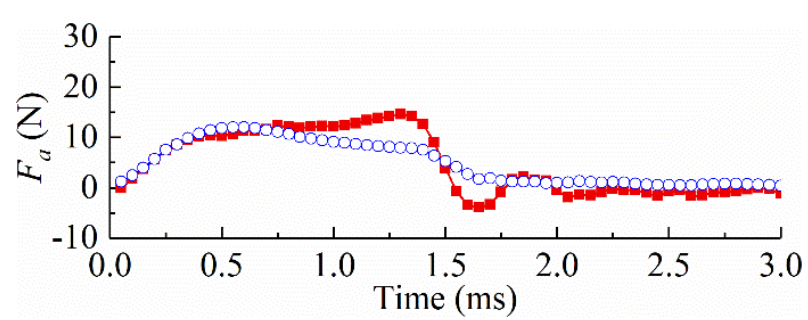

(b)
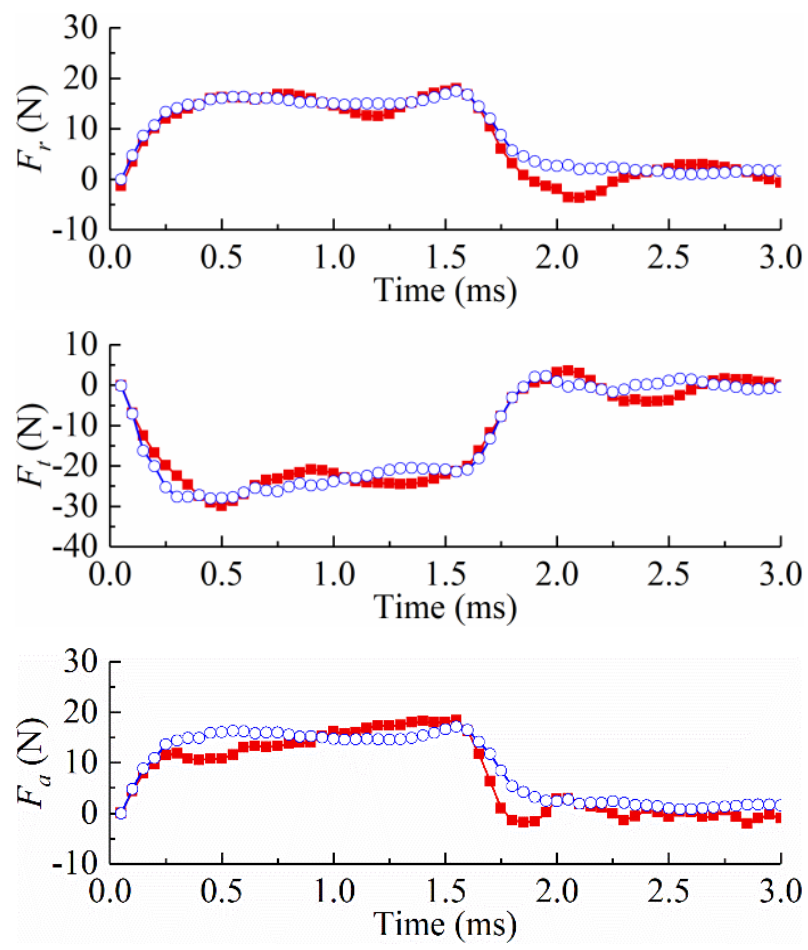

(d)

$\longrightarrow$ Dynamometer $\longrightarrow$ Instrumented cutter

Fig. 9. Comparison of cutting forces measured from the dynamometer and the instrumented cutter for different spindle speed and axial cutting depth. (a) Spindle speed: 1000rpm, cutting depth: 0.4mm. (b) Spindle speed 1500rpm, cutting depth: $0.4 \mathrm{~mm}$. (c) Spindle speed: 1000rpm, cutting depth: 0.6mm. (d) Spindle speed: 1500rpm, cutting depth: $0.6 \mathrm{~mm}$.

\subsection{Validation of cutting forces monitoring for separate insert}

To validate the single phase cutting force monitoring performance of the instrumented cutter system in milling process, milling tests with new, worn and chipped inserts were performed, as shown in Fig. 10. The diameter of the cutter was $32 \mathrm{~mm}$, the workpiece material was Aluminium alloy 7075. Cutting parameters were set as: axial depth of cut $0.9 \mathrm{~mm}$, radial depth of cut $0.3 \mathrm{~mm}$, spindle speed $600 \mathrm{r} / \mathrm{min}$, feedrate $100 \mathrm{~mm} / \mathrm{min}$. Sampling frequency of each channel for both the dynamometer and the instrumented cutter is set to $10 \mathrm{kHz}$. Cutting forces from the workpiece side were also recorded by the table dynamometer. 


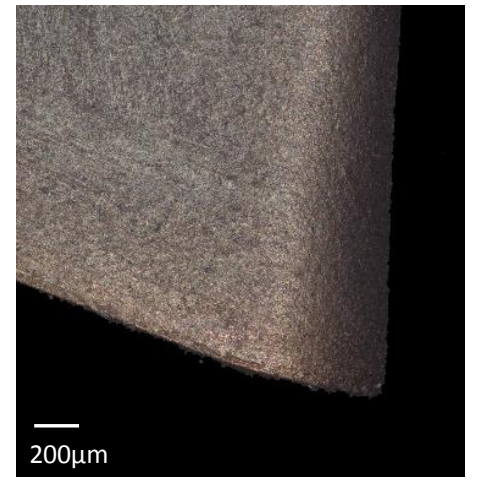

(a)

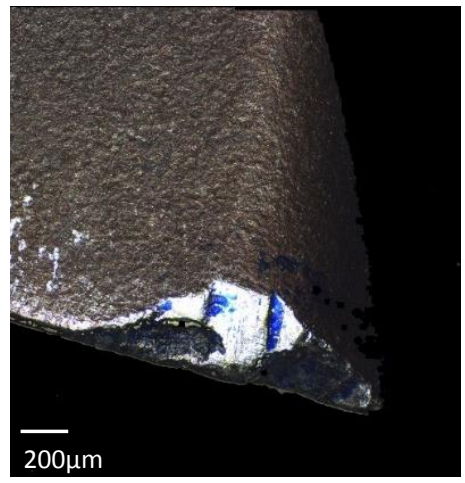

(b)

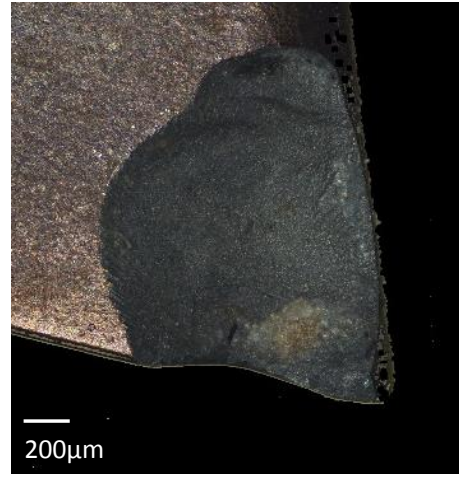

(c)

Fig. 10. Photos taken by Alicona Infinitefocus G4 for inserts used in milling tests. (a) New insert. (b) Worn insert. (c) Inserts with flank edge chipped.

The 3 directions cutting forces recorded by the dynamometer and the developed instrumented cutter are compared and shown in Fig. 11. Indicating that worn insert results in the largest force amplitude, and the chipped insert provides the smallest forces. As for the time period, worn insert has almost the same time period with new insert during one insert cutting process, which is about $4.5 \mathrm{~ms}$, while the cutting time about $4.0 \mathrm{~ms}$ for chipped insert is a little shorter. Since the insert cutting edge is chipped, the effective cutter radius is bit smaller than new insert. Therefore, the actual chip thickness is a bit smaller thus leading to lower cutting force and shorter cutting time period.

Cutting forces recorded by the developed instrumented cutter come to the same conclusion as the dynamometer signals demonstrate: the worn insert results in the largest force, and the chipped insert results in the smallest force. Among three PVDF sensors, the first one recorded the largest force, which is corresponding to the tangential direction force. The second PVDF sensor also recorded large force, it shares a large portion of radial cutting force. The third PVDF sensor recorded the smallest force, which is relative to the axial cutting force. Furthermore, the signals recorded from the PVDF sensors show a satisfactory agreement with the dynamometer measured signals. Indicating that the developed instrument cutter works well and could distinguish the single cutter insert condition. 

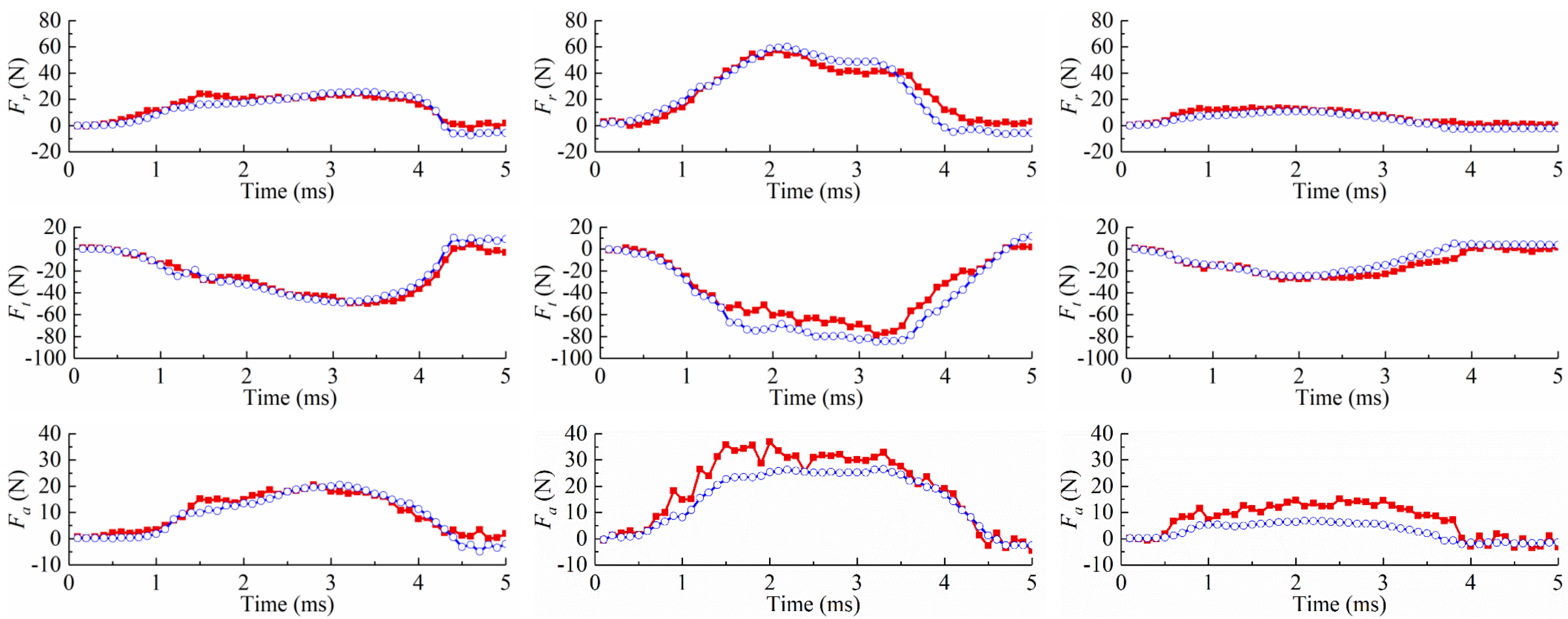

(a)

(b)

(c)

$$
\longrightarrow \text { Dynamometer —— Instrumented cutter }
$$

Fig. 11. Comparison of forces in three directions with signals from the dynamometer and instrumented cutter for (a) new, (b) worn and (c) chipped inserts. 
The deformed chips for three inserts are presented in Fig. 12. For the new insert, the deformed chip has relatively regular shape (see Fig. 12a). For the worn insert, since the cutting edge is not sharp anymore, there exists the extrusion between the insert and the workpiece material, which results in large force. For the chipped insert, it cuts less amount of material and the force is much smaller. By comparing recorded cutting forces in Fig. 11 and deformed chips in Fig. 12, it is clear that the developed instrumented cutter can identify the abnormal phenomenon from the cutter for different inserts in the milling process. Both experimented comparison results and theoretical analysis show clearly the advantages of the developed instrumented cutter system. It shins the lights on fast and accurate cutter wear monitoring and estimation in production line.

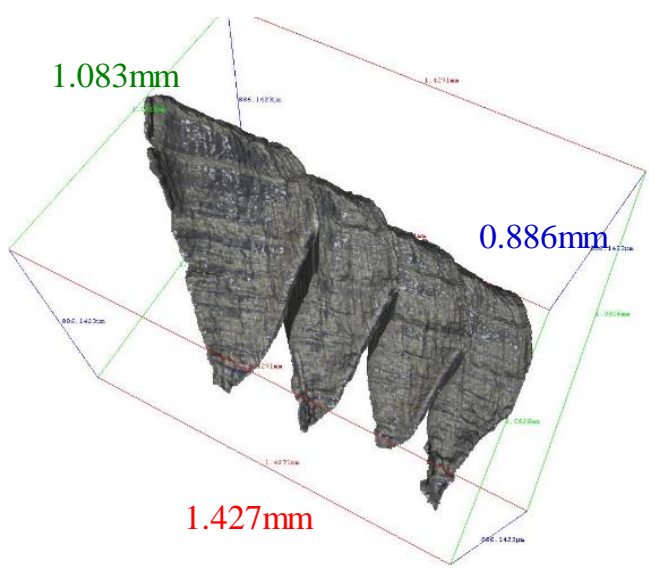

(a)

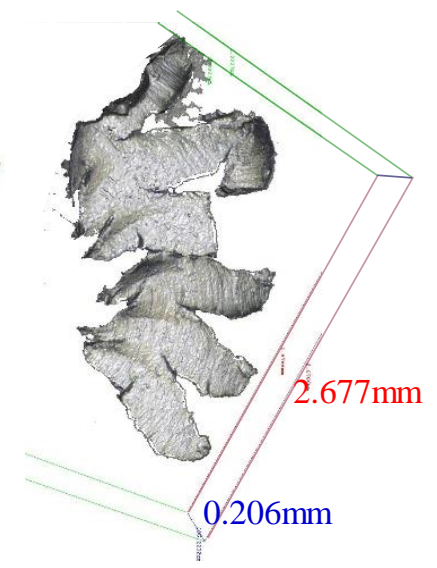

(b)

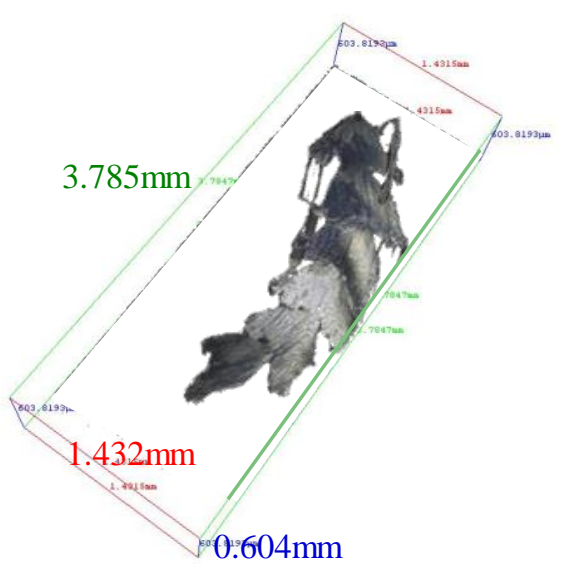

(c)

Fig. 12. Deformed chip for three inserts. (a) New insert. (b) Worn insert. (c) Chipped insert.

\section{Conclusions}

A novel instrumented milling cutter system with embedded thin film sensors is proposed, modelled and validated in this paper. The advantage of using such cutter over the off-the-shelf dynamometers is that it can be used for measuring forces on each cutting edge as well as to identify cutter edge malfunctions separately. Furthermore, the developed system can be implanted in the production lines with minimal disturbance of the machining systems. The main contributions of this paper can be concluded as follows:

- Thin film sensors are embedded into the cutter for separate insert to monitor the specific cutting forces acting on single milling tooth, and for the first time the accurate on-line estimation of the separate inserts' working conditions is achieved.

- A dedicated milling force decoupling model to overcome cross-talk due to non-orthogonal placement of sensors for the developed instrumented milling cutter system is proposed, enabling the estimation of the separate inserts' working conditions by analysing the cutting 
forces acting on the insert.

- The validation demonstrates that the presented monitoring system prototype could measure the cutting forces accurately compared with the dynamometer with the error less than $10 \%$. Furthermore, the proposed instrumented milling cutter system with embedded thin film sensors could also identify the tool insert conditions such as worn and chipped, such information cannot be obtained from the dynamometer.

Therefore, the developed instrumented milling cutter could be directly used in the workshop to ensure the high-value added parts are machined properly since the tool conditions of each insert are monitored and estimated during the whole machining process. Furthermore, the developed instrumented cutter also opens avenue for analysing insert failure mechanism and its progress by collecting the single insert's force data. Further research to overcome some limitations of the developed system such as, embedding sensors directly under the insert as well as to improve the wireless transmission rate will be carried out.

\section{Acknowledgments}

This work was supported by the Royal Society - NSFC project under Grant no. 51611130191.

\section{References}

[1] D. Zhu, X. Zhang, H. Ding, Tool wear characteristics in machining of nickel-based superalloys, Int. J. Mach. Tools Manuf. 64 (2013) 60-77. doi:10.1016/j.ijmachtools.2012.08.001.

[2] R. M'Saoubi, D. Axinte, S.L. Soo, C. Nobel, H. Attia, G. Kappmeyer, S. Engin, W.M. Sim, High performance cutting of advanced aerospace alloys and composite materials, CIRP Ann. Manuf. Technol. 64 (2015) 557-580. doi:10.1016/j.cirp.2015.05.002.

[3] Q. Yao, M. Luo, D. Zhang, B. Wu, Identification of cutting force coefficients in machining process considering cutter vibration, Mech. Syst. Signal Process. 103 (2018) 39-59. doi:10.1016/j.ymssp.2017.09.038.

[4] A. Gameros, S. Lowth, D. Axinte, A. Nagy-Sochacki, O. Craig, H.R. Siller, State-of-the-art in fixture systems for the manufacture and assembly of rigid components: A review, Int. J. Mach. Tools Manuf. 123 (2017) 1-21. doi:10.1016/j.ijmachtools.2017.07.004.

[5] Y.H. Jeong, D.W. Cho, Estimating cutting force from rotating and stationary feed motor currents on a milling machine, Int. J. Mach. Tools Manuf. 42 (2002) 1559-1566. doi:10.1016/S0890-6955(02)00082-2.

[6] S. Auchet, P. Chevrier, M. Lacour, P. Lipinski, A new method of cutting force measurement based on command voltages of active electro-magnetic bearings, Int. J. Mach. Tools Manuf. 44 (2004) 1441-1449.

[7] D. Axinte, N. Gindy, Assessment of the effectiveness of a spindle power signal for tool condition monitoring in machining processes, Int. J. Prod. Res. 42 (2004) 2679-2691. doi:10.1080/00207540410001671642.

[8] D. Shi, N.N. Gindy, Industrial Applications of Online Machining Process Monitoring System, 
Mechatronics, IEEE/ASME Trans. 12 (2007) 561-564. doi:10.1109/TMECH.2007.902131.

[9] Y. Li, C. Liu, X. Hao, J.X. Gao, P.G. Maropoulos, Responsive fixture design using dynamic product inspection and monitoring technologies for the precision machining of large-scale aerospace parts, CIRP Ann. - Manuf. Technol. 64 (2015) 173-176. doi:10.1016/j.cirp.2015.04.025.

[10] G. Totis, G. Wirtz, M. Sortino, D. Veselovac, E. Kuljanic, F. Klocke, Development of a dynamometer for measuring individual cutting edge forces in face milling, Mech. Syst. Signal Process. 24 (2010) 1844-1857. doi:10.1016/j.ymssp.2010.02.010.

[11] M. Liu, Z. Zhang, Z. Zhou, S. Peng, Y. Tan, Mechatronics A new method based on Fiber Bragg grating sensor for the milling force measurement, Mechatronics. 31 (2015) 22-29. doi:10.1016/j.mechatronics.2015.03.007.

[12] C. Wang, K. Cheng, X. Chen, T. Minton, R. Rakowski, Design of an instrumented smart cutting tool and its implementation and application perspectives, Smart Mater. Struct. 23 (2014) 35019. doi:10.1088/0964-1726/23/3/035019.

[13] Y. Zhao, Y. Zhao, C. Wang, S. Liang, R. Cheng, Y. Qin, P. Wang, Y. Li, X. Li, T. Hu, Design and development of a cutting force sensor based on semi-conductive strain gauge, Sensors Actuators, A Phys. 237 (2016) 119-127. doi:10.1016/j.sna.2015.11.017.

[14] L. Cen, S.N. Melkote, J. Castle, H. Appelman, A Wireless Force-Sensing and Model-Based Approach for Enhancement of Machining Accuracy in Robotic Milling, IEEE/ASME Trans. Mechatronics. 21 (2016) 2227-2235. doi:10.1109/TMECH.2016.2567319.

[15] Y. Ting, Suprapto, A. Nugraha, C.W. Chiu, H. Gunawan, Design and characterization of onelayer PVDF thin film for a 3D force sensor, Sensors Actuators, A Phys. 250 (2016) 129-137. doi:10.1016/j.sna.2016.09.025.

[16] L. Ma, S.N. Melkote, J.B. Morehouse, J.B. Castle, J.W. Fonda, M.A. Johnson, Thin-Film PVDF Sensor-Based Monitoring of Cutting Forces in Peripheral End Milling, J. Dyn. Syst. Meas. Control. 134 (2012) 51014. doi:10.1115/1.4006366.

[17] Z. Fan, X. Zou, R.X. Gao, M.K. Ng, J. Cao, E.F. Smith, Embedded capacitive pressure sensing for electrically assisted Microrolling, IEEE/ASME Trans. Mechatronics. 20 (2015) 1005-1014. doi:10.1109/TMECH.2014.2365512.

[18] I. Marinescu, D. A. Axinte, A critical analysis of effectiveness of acoustic emission signals to detect tool and workpiece malfunctions in milling operations, Int. J. Mach. Tools Manuf. 48 (2008) 1148-1160.

[19] P.F. Sensors, Technical Manual, Meas. Spec. Inc. 25 (2008).

[20] A. Khan, Z. Abas, H. Soo Kim, I.K. Oh, Piezoelectric thin films: An integrated review of transducers and energy harvesting, Smart Mater. Struct. 25 (2016) 53002. doi:10.1088/0964$1726 / 25 / 5 / 053002$.

[21] C.C. Ma, K.C. Chuang, S.Y. Pan, Polyvinylidene fluoride film sensors in collocated feedback structural control: Application for suppressing impact-induced disturbances, IEEE Trans. Ultrason. Ferroelectr. Freq. Control. 58 (2011) 2539-2554. doi:10.1109/TUFFC.2011.2117.

[22] J. Yi, A Piezo-Sensor-Based "Smart Tire" System for Mobile Robots and Vehicles, IEEE/ASME Trans. Mechatronics. 13 (2008) 95-103. doi:10.1109/TMECH.2007.915064. 
[23] J. Sirohi, I. Chopra, Fundamental Understanding of Piezoelectric Strain Sensors, J. Intell. Mater. Syst. Struct. 11(2000) 246-257.

[24] R.C. Hibbeler, Mechanics of Material 6th Edition Pearson Prentice-Hall, Up. Saddle River, NJ. (2005). 